Jurnal Keperawatan Silampari

Volume 5, Nomor 1, Desember 2021

e-ISSN: 2581-1975

p-ISSN: 2597-7482

DOI: https://doi.org/10.31539/jks.v5i1.2958

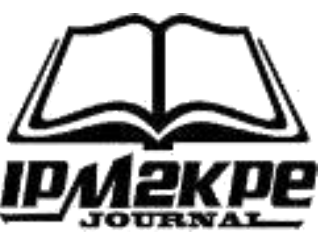

\title{
MODUL ENAM SASARAN KESELAMATAN PASIEN \\ DALAM PEMBELAJARAN KLINIK TERHADAP PERILAKU MAHASISWA KEPERAWATAN
}

\author{
Efitra $^{1}$, Reflita $^{2}$ \\ Politeknik Kesehatan Kementerian Kesehatan Padang ${ }^{1,2}$ \\ efitra.kep@gmail.com ${ }^{1}$
}

\begin{abstract}
ABSTRAK
Penelitian ini bertujuan untuk mengetahui efektifitas penggunaan modul 6 sasaran keselamatan pasien dalam pembelajaran klinik terhadap perubahan perilaku mahasiswa keperawatan di RSAM Bukittinggi. Penelitian ini merupakan penelitian quasi eksperimen dengan pretest posttest control group design. Hasil penelitian menunjukkan bahwa pada kelompok kontrol didapatkan rata-rata 23 dan 28,40 pada kelompok perlakuan. Sikap didapatkan rata-rata 51,27 pada kelompok kontrol dan 59,6 pada kelompok perlakuan. Selanjutnya untuk tindakan didapatkan rata-rata 28,93 pada kelompok kontrol dan 39,6 pada kelompok perlakuan. Analisis perilaku menunjukkan p-value $<0,05$. Simpulan, modul 6 sasaran keselamatan pasien efektif dalam peningkatan pengetahuan dan tindakan atau penerapan sasaran keselamatan pasien.
\end{abstract}

Kata Kunci: Modul 6 Sasaran Keselamatan Pasien, Pembelajaran Klinik

\section{ABSTRACT}

This study aims to determine the effectiveness of module 6 patient safety goals in clinical learning on behavioral changes in nursing students at RSAM Bukittinggi. This research is a quasi-experimental research with a pretest-posttest control group design. The results showed that the control group obtained an average of 23 and 28.40 in the treatment group. Attitudes received an average of 51.27 in the control group and 59.6 in the treatment group. Furthermore, the action obtained an average of 28.93 in the control group and 39.6 in the treatment group. Behavioral analysis showed a p-value <0.05. In conclusion, module 6 patient safety goals effectively increase knowledge and actions or implement patient safety goals.

Keywords: Module 6 Patient Safety Goals, Clinical Learning

\section{PENDAHULUAN}

Keselamatan pasien merupakan suatu sistem yang membuat asuhan pasien lebih aman, meliputi asesmen risiko, identifikasi dan pengelolaan risiko pasien, pelaporan dan analisis insiden, kemampuan belajar dari insiden dan tindak lanjutnya, serta implementasi solusi untuk meminimalkan timbulnya risiko dan mencegah terjadinya cedera yang disebabkan oleh kesalahan akibat melaksanakan suatu tindakan atau tidak mengambil tindakan yang seharusnya diambil (Nuryanti, 2018). 
Keselamatan pasien adalah kunci penting bagi setiap fasilitas kesehatan. Hal ini pula yang menjadi indikator sangat penting dalam penilaian sebuah rumah sakit (Neri et al., 2018). Pengaturan keselamatan pasien bertujuan untuk meningkatkan mutu pelayanan fasilitas pelayanan kesehatan melalui penerapan manajemen risiko dalam seluruh aspek pelayanan yang disediakan oleh fasilitas pelayanan kesehatan (Faluzi et al., 2019).

Penyelenggaraan keselamatan pasien salah satunya dilakukan melalui pembentukan sistem pelayanan yang menerapkan sasaran keselamatan pasien. Sasaran Keselamatan Pasien (SKP) di Indonesia mengacu kepada Internatinal Patient Safety Goals (IPSG) (Haritsa \& Haskas, 2021). SKP merupakan hal sangat penting untuk dipahami dan diterapkan dalam praktik asuhan keperawatan. Sasaran keselamatan pasien adalah syarat yang harus diterapkan di semua rumah sakit (Fraditha, 2019).

Tujuan SKP adalah untuk menggiatkan perbaikan-perbaikan tertentu dalam soal keselamatan pasien. Sasaran dalam SKP menyoroti bidang-bidang yang bermasalah dalam perawatan kesehatan, memberikan bukti dan solusi hasil konsensus yang berdasarkan nasihat para pakar (Helsanewa et al., 2019). Dengan mempertimbangkan bahwa untuk menyediakan perawatan kesehatan yang aman dan berkualitas tinggi diperlukan desain sistem yang baik, sasaran biasanya sedapat mungkin berfokus pada solusi yang berlaku untuk keseluruhan sistem (Budi et al., 2019).

Sasaran keselamatan pasien meliputi tercapainya hal-hal yang berkaitan dengan mengidentifikasi pasien dengan benar, meningkatkan komunikasi yang efektif, meningkatkan keamanan obat-obatan yang harus diwaspadai, memastikan lokasi pembedahan yang benar, prosedur yang benar, pembedahan pada pasienyang benar dan mengurangi risiko infeksi akibat perawatan kesehatan serta mengurangi risiko cedera pasien akibat terjatuh (Budi et al., 2019).

Identifikasi pasien yang benar dimulai dengan kontak pertama pasien dengan pelayanan. Identifkasi pasien merupakan tanggungjawab semua staf yang terlibat dalam proses penerimaan, klinis dan administratif untuk memastikan rincian yang benar diperoleh dan dicatat. Identifikasi pasien meliputi identifikasi identitas dan identifikasi resiko (Nuryanti, 2018). Setiap ketidakakuratan atau pertanyaan ditangani, keadaan yang dapat mengarahkan terjadinya error/ kesalahan dalam mengidentifikasi pasien, adalah pasien yang dalam keadaan terbius/ tersedasi, mengalami disorientasi atau tidak sadar sepenuhnya, mungkin bertukar tempat tidur, kamar, lokasi di dalam fasilitas pelayanan kesehatan, mungkin mengalami disabilitas sensori atau akibat situasi lain. Kesalahan mengidentifikasi pasien dengan benar merupakan risiko serius terhadap keselamatan pasien (Fenita, 2019).

Sasaran kedua dari keselamatan pasien merupakan cara untuk mengembangkan pola pendekatan agar komunikasi bisa berjalan dengan efektif (Supatri, 2018). Hal ini bertujuan agar komunikasi lisan terjadi dengan akurat, sehingga informasinya bisa diterapkan secara konsisten. Sedangkan sasaran ketiga merupakan cara yang dilakukan agar memastikan obat tetap aman untuk diberikan kepada pasien. Prosedur ini berkaitan dengan proses identifikasi, pemberian label, penetapan lokasi dan penyimpanannya (Surahmat et al., 2019). Sasaran keselamatan pasien yang ke empat merupakan kegiatan yang diaplikasikan agar pasien tercatat dengan valid sebelum mendapatkan tindakan operasi. Selanjutnya sasaran ke lima merupakan prosedur dalam pencegahan penyakit menular dan infeksi sesuai dengan pedomannya. Penekanan pada sasaran ke enam adalah bahwa setiap tenaga medis harus memahami dan mengaplikasikan sejumlah langkah untuk memastikan pasien tidak mengalami risiko jatuh (Jelita, 2019). Semua langkah akan diawasi untuk memastikan keberhasilannya. Dengan begitu segala risiko tersebut tidak akan menimpa pasien yang sedang dirawatnya. 
Pelaksanaan sasaran keselamatan pasien yang tidak sesuai standar akan berdampak terhadap keselamatan pasien, seperti adanya Kejadian Tidak Diharapkan (KTD), Kejadian Nyaris Cedera (KNC), Kejadian Tidak Cedera (KTC), Kondisi Potensial Cedera (KPC), dan kejadian sentinel atau sentinel event (Nugraheni et al., 2021). Pada tahun 2014 WHO mempublikasikan KTD rumah sakit berbagai negara yaitu Amerika, Inggris, Denmark dan Australia terjadi dengan rentang 3,2-16,6 \%. Laporan keselamatan pasien rumah sakit (KKP-RS) di Indonesia pada bulan Januari-April 2011, menemukan bahwa adanya pelaporan kasus KTD 14,4 \% dan kejadian nyaris cedera 18,5 \% yang disebabkan karena proses atau prosedur klinik 9,26 \%, medikasi 9,26\%, dan pasien jatuh 5,15\%. Berdasarkan wawancara dengan Kepala Bidang SDM RSAM Bukittinggi didapatkan bahwa KTD tidak ditemukan, namun KNC yang disebabkan mahasiswa sering ditemukan hanya keadaan ini tidak terdokumentasi.

Hasil penelitian Sapardi tentang analisis pelaksanaan manajemen pencegahan dan pengendalian helthcare associated infections di RSI Ibnu Sina didapatkan empat tema yaitu: pelaksanaan program HAIs, penerapan manajemen pelaksanaan HAIs dan hasil penerapan HAIs belum optimal (Sapardi et al., 2018). Selanjutnya juga ditemukan hambatan dalam pelaksanaan antara lain perilaku petugas kesehatan, masih kurangnya kompetensi perawat dan upaya pencegahan dan pengendalian HAIs.

Kondisi di atas tidak akan terjadi apabila petugas kesehatan yang salah satunya adalah perawat dalam melakukan enam sasaran keselamatan pasien dengan benar. Berdasarkan wawancara dengan salah seorang perawat di Rumah Sakit Umum Ahmad Muchtar menjelaskan belum ada panduan atau modul tentang penerapan enam sasaran keselamatan pasien yang merupakan pedoman bagi perawat dalam praktik maupun dalam membimbing proses pembelajaran klinik mahasiswa di rumah sakit. Modul merupakan salah satu media pembelajaran yang dapat memfasilitasi mahasiswa untuk mencapai kompetensi.

Penggunaan alat bantu atau media akan mempermudah penerimaan informasi sehingga akan mempercepat terjadinya perubahan prilaku. Menurut penelitian para ahli, indra yang paling banyak menyalurkan pengetahuan adalah mata. Kurang lebih $75 \%$ - 87\%, pengetahuan manusia diperoleh dari mata. Salah satu alat atau media yang digunakan untuk mempermudah informasi adalah penggunaan modul atau booklet (Mudayana \& Juniarti, 2018). Modul (booklet) adalah suatu media untuk menyampaikan pesan-pesan kesehatan dalam bentuk buku, baik berupa tulisan atau gambar.

Pada penelitian ini, peneliti menjadikan mahasiswa sebagai subbjek penelitian yang merupakan cikabakal perawat masadepan. Melalui penelitian ini peneliti menggunakan sebuah modul dan mengetahui keefektifan dari modul tersebut. Selain itu, belum ada penelitian sebelumnya yang sama dengan penelitian ini khususnya di tempat penelitian.

\section{METODE PENELITIAN}

Penelitian ini merupakan penelitian eksperimental ulang dengan pretest and posttest control group design yaitu melakukan pengukuran awal sebelum dan sesudah diberikan perlakuan. Rancangan ini akan didapatkan hasil apakah suatu perlakuan mempunyai pengaruh terhadap perlakuan dan kelompok kontrol. Pengukuran sebelum dan sesudah diberikan perlakukan dilakukan sebanyak 2 kali yaitu pada awal pertama kali atau pre-test setelah itu 10 hari sesudah pre-test dilanjutkan pengukuran ke dua atau post-test. 


\section{HASIL PENELITIAN}

\section{Analisa Univariat}

Tingkat Pengetahuan

Tabel. 1

Distribusi Frekuensi Responden (Kelompok Kontrol)

Berdasarkan Tingkat Pengetahuan tentang Enam Sasaran Keselamatan Pasien

\begin{tabular}{ccccc}
\hline \multirow{2}{*}{ Pengetahuan } & \multicolumn{2}{c}{ Frekuensi } & \multicolumn{2}{c}{ Persentase $(\%)$} \\
\cline { 2 - 5 } & Sebelum & Sesudah & Sebelum & Sesudah \\
\hline Tinggi & 0 & 2 & 0 & 13,3 \\
Rendah & 15 & 13 & 100 & 86,7 \\
\hline Total & 15 & 15 & 100 & 100 \\
\hline
\end{tabular}

Berdasarkan tabel 1 dapat kita lihat bahwa, pada kelompok kontrol sebelum dilakukan memiliki tingkat pendidikan yang rendah dengan persentasi yang merata yaitu $100 \%$. Ketika dilakukan kelompok memasuki masa praktek selama 9 hari, ditemukan hanya 2 orang atau 13,3\% dari keseluruhan anggota kelompok yang memeiliki tingkat pengetahuan tinggi.

Tabel. 2

Distribusi Frekuensi Responden (Kelompok Perlakuan)

Berdasarkan Tingkat Pengetahuan tentang Enam Sasaran Keselamatan Pasien

\begin{tabular}{lcccc}
\hline & \multicolumn{2}{c}{ Frekuensi } & \multicolumn{2}{c}{ Persentase (\%) } \\
\cline { 2 - 5 } Pengetahuan & sebelum & Sesudah & Sebelum & Sesudah \\
\hline Tinggi & 1 & 11 & 6,7 & 73,3 \\
Rendah & 14 & 4 & 93,3 & 26,7 \\
\hline Total & 15 & 15 & 100 & 100 \\
\hline
\end{tabular}

Berdasarkan tabel 2 menunjukan bahwa terjadi peningkatan tingkat pengetahuan responden tentang enam sasaran keselamatan pasien setelah diberikan perlakuan (modul) yaitu dari $6,7 \%$ menjadi $73,3 \%$ yang berpengetahuan tinggi. Hal ini terjadi peningkatan setelah diberikan perlakuan bahwa terdapat 10 orang responden berhasil meningkatkan penegtahuan melalui penggunaan modul.

\section{Sikap}

Tabel. 3

Distribusi Frekuensi Responden (Kelompok Kontrol)

Berdasarkan Sikap tentang Enam Sasaran Keselamatan Pasien

\begin{tabular}{ccccc}
\hline Sikap & \multicolumn{2}{c}{ Frekuensi } & \multicolumn{2}{c}{ Persentase (\%) } \\
\cline { 2 - 5 } & Sebelum & Sesudah & Sebelum & Sesudah \\
\hline Positif & 4 & 0 & 26.7 & 0 \\
Negatif & 11 & 15 & 73.3 & 100 \\
\hline Total & 15 & 15 & 100 & 100 \\
\hline
\end{tabular}

Berdasarkan tabel 3 menunjukan bahwa responden pada kelompok kontrol sebelum praktek hanya sedikit sekali $(26,7 \%)$ yang bersikap positif terhadap enam sasaran keselamatan pasien, namun setelah berpraktek selama 9 hari tidak ada responden yang bersikap positif. 
Tabel. 4

Distribusi Frekuensi Responden (Kelompok Kontrol)

Berdasarkan Tindakan tentang 6 Sasaran Keselamatan Pasien

\begin{tabular}{ccccc}
\hline \multirow{2}{*}{ Tindakan } & \multicolumn{2}{c}{ Frekuensi } & \multicolumn{2}{c}{ Persentase (\%) } \\
\cline { 2 - 5 } & Sebelum & Sesudah & Sebelum & Sesudah \\
\hline Tinggi & 0 & 1 & 0 & 6,7 \\
Rrndah & 15 & 14 & 100 & 93,3 \\
\hline Total & 15 & 15 & 100 & 100 \\
\hline
\end{tabular}

Berdasarkan tabel 4 menunjukan bahwa sikap responden kelompok perlakuan terhadap enam sasaran keselamatan pasien lebih banyak yang bersikap positif dibandingkan yang negatif. Selanjutnya hasil penelitian juga menunjukan bahwa tidak perubahan sikap responden antara sebelum dan sesudah perlakuan.

\section{Tindakan}

Tabel. 5

Distribusi Frekuensi Responden (Kelompok Kontrol)

Berdasarkan Tindakan tentang 6 Sasaran Keselamatan Pasien

\begin{tabular}{ccccc}
\hline \multirow{2}{*}{ Tindakan } & \multicolumn{2}{c}{ Frekuensi } & \multicolumn{2}{c}{ Persentase $(\%)$} \\
\cline { 2 - 5 } & Sebelum & Sesudah & Sebelum & Sesudah \\
\hline Tinggi & 0 & 1 & 0 & 6,7 \\
Rrndah & 15 & 14 & 100 & 93,3 \\
\hline Total & 15 & 15 & 100 & 100 \\
\hline
\end{tabular}

Berdasarkan tabel 5 menunjukan bahwa tindakan responden kelompok kontrol terhadap enam sasaran keselamatan pasien hampir semua dengan tindakan rendah, baik sebelum praktek maupun setelah 9 hari praktik.

Tabel. 6

Distribusi Frekuensi Responden (Kelompok Perlakuan)

Berdasarkan Tindakan tentang Enam Sasaran Keselamatan Pasien

\begin{tabular}{ccccc}
\hline \multirow{2}{*}{ Tindakan } & \multicolumn{2}{c}{ Frekuensi } & \multicolumn{2}{c}{ Persentase (\%) } \\
\cline { 2 - 5 } & Sebelum & Sesudah & Sebelum & Sesudah \\
\hline Baik & 0 & 14 & 0 & 93,3 \\
Kurang & 15 & 1 & 100 & 6,7 \\
\hline Total & 15 & 15 & 100 & 100 \\
\hline
\end{tabular}

Berdasarkan tabel 6 menunjukan bahwa responden kelompok perlakuan lebih banyak memiliki tindakan yang baik setelah diberikan perlakuan berupa modul, hal ini dapat terlihat meningkatnya jumlah objek penelitian sebanyak 14 orang atau 93,3\% yang memiliki tindakan.

Tabel. 7

Analisis Pengetahuan Responden pada Kelompok Kontrol tentang Enam sasaran Keselamatan Pasien

\begin{tabular}{ccccc}
\hline Pengetahuan & Mean & Minimum & Maximum & Std. Deviasi \\
\hline Sebelum & 23,67 & 19 & 27 & 2,410 \\
Sesudah & 23 & 14 & 29 & 3,723 \\
\hline
\end{tabular}


Berdasarkan tabel 7 menunjukan bahwa rata-rata pengetahuan responden pada kelompok kontrol setelah praktek sedikit lebih rendah dibandingkan sebelum praktik. Selanjutnya nilai minimun lebih kecil dari sebelum praktik, dan nilai maksimun lebih tinggi sesudah praktik dengan standar deviasi 3,723.

Tabel. 8

Analisis Pengetahuan Responden pada Kelompok Perlakuan tentang Enam sasaran Keselamatan Pasien

\begin{tabular}{ccccc}
\hline Pengetahuan & Mean & Minimum & Maximum & Std. Deviasi \\
\hline Sebelum & 24,47 & 20 & 28 & 2,066 \\
Sesudah & 28,40 & 26 & 31 & 1,502 \\
\hline
\end{tabular}

Berdasarkan tabel 8 menunjukan bahwa rata- rata pengetahuan responden pada kelompok perlakuan setelah perlakuan meningkat dibandingkan sebelum perlakuan. Selanjutnya nilai minimun lebih tinggi dari sebelum perlakuan, dan nilai maksimun lebih tinggi sesudah perlakuan dengan standar deviasi 1,502.

Tabel. 9

Analisis Sikap Responden pada kelompok Kontrol tentang Enam Sasaran Keselamatan Pasien

\begin{tabular}{ccccc}
\hline Sikap & Mean & Minimum & Maximum & Std. Deviasi \\
\hline Sebelum & 56,33 & 45 & 62 & 4,371 \\
Sesudah & 51,27 & 46 & 58 & 4,652 \\
\hline
\end{tabular}

Berdasarkan tabel 9 menunjukan bahwa rata- rata sikap responden pada kelompok kontrol setelah praktek lebih rendah dibandingkan sebelum praktek. Selanjutnya nilai minimun lebih tinggi dari sebelum praktek, dan nilai maksimun lebih rendah sesudah praktek dengan standar deviasi 4,652.

Tabel. 10

Analisis Sikap Responden pada Kelompok Perlakuan tentang Enam Sasaran Keselamatan Pasien

\begin{tabular}{lcccc}
\hline Sikap & Mean & Minimum & Maximum & Std.Deviasi \\
\hline Sebelum & 58,8 & 52 & 63 & 3,745 \\
Sesudah & 59,6 & 45 & 70 & 6,468 \\
\hline
\end{tabular}

Berdasarkan tabel 10 menunjukan bahwa rata- rata sikap responden pada kelompok perlakuan setelah perlakuan lebih positif dibandingkan sebelum perlakuan. Selanjutnya nilai minimun lebih rendah dari sebelum perlakuan, dan nilai maksimun lebih tinggi sesudah perlakuan dengan standar deviasi 6,468.

Tabel. 11

Analisis Tindakan Responden pada Kelompok Kontrol tentang Enam Sasaran Keselamatan Pasien

\begin{tabular}{lcccc}
\hline Tindakan & Mean & Minimum & Maximum & Std.Deviasi \\
\hline Sebelum & 14,73 & 3 & 32 & 11,035 \\
Sesudah & 28,93 & 22 & 36 & 4,217 \\
\hline
\end{tabular}


Berdasarkan tabel 11 menunjukan bahwa rata- rata tindakan responden pada kelompok kontrol sesudah praktek lebih baik dibandingkan sebelum praktek. Selanjutnya nilai minimun lebih tinggi dari sebelum praktek, dan nilai maksimun lebih tinggi sesudah praktek dengan standar deviasi 4,217.

Tabel. 12

Analisis Tindakan Responden pada Kelompok Perlakuan tentang Enam Sasaran Keselamatan pasien Tahun 2019 ( $n=15)$

\begin{tabular}{lcccc}
\hline Tindakan & Mean & Minimum & Maximum & Std.Deviasi \\
\hline Sebelum & 20,67 & 17 & 28 & 3,478 \\
Sesudah & 39,6 & 31 & 43 & 3,376 \\
\hline
\end{tabular}

Berdasarkan tabel 12 menunjukan bahwa rata- rata tindakan responden pada kelompok perlakuan lebih baik dibandingkan sebelum perlakuan. Selanjutnya nilai minimun lebih tinggi dari sebelum perlakuan, dan nilai maksimun lebih tinggi sesudah perlakuan dengan standar deviasi 3,376.

\section{Analisis Bivariat}

\section{Pengetahuan}

Tabel. 13

Analisis Hasil Pre Tes Pengetahuan Responden pada Kelompok Kontrol dan Perlakuan tentang 6 Sasaran Keselamatan Pasien

\begin{tabular}{lccccc}
\hline Pengetahuan & $\mathrm{n}$ & Mean & Std. Deviasi & Std.error & P Value \\
\hline Kontrol & 15 & 23,67 & 2,410 & 0,622 & \multirow{2}{*}{0,338} \\
Perlakuan & 15 & 24,47 & 2,066 & 0,533 & \\
\hline
\end{tabular}

Berdasarkan tabel menunjukan pada tahap pre tes nilai rata-rata pengetahuan responden tentang 6 sasaran keselamatan pasien lebih tinggi pada kelompok perlakuan dibandingkan dengan kelompok kontrol. Hasil uji statistik didapatkan pada variabel pengetahuan dengan nilai $\mathrm{P}=0,338$ berarti pada alpha 5\% maka nilai $\mathrm{P}>0,05$ artinya tidak ada perbedaan yang signifikan pengetahuan antara kelompok kontrol dengan kelompok perlakuan.

Tabel. 14

Analisi Hasil Post Tes Pengetahuan Responden pada Kelompok Kontrol dan Perlakuan tentang Enam Sasaran Keselamatan Pasien

\begin{tabular}{lccccc}
\hline Pengetahuan & $\mathrm{n}$ & Mean & Std. Deviasi & Std.error & \multirow{2}{*}{ P Value } \\
\hline Kontrol & 15 & 23,00 & 3,723 & 0,961 & \multirow{2}{*}{0,0001} \\
Perlakuan & 15 & 24,40 & 1,502 & 0,388 & \\
\hline
\end{tabular}

Berdasarkan tabel 14 menunjukan pada tahap post-test nilai rata-rata pengetahuan responden tentang enam sasaran keselamatan pasien lebih tinggi pada kelompok perlakuan dibandingkan dengan kelompok kontrol. Hasil uji statistik didapatkan pada variabel pengetahuan dengan nilai $\mathrm{P}=0,0001$ berarti pada alpha 5\% maka nilai $\mathrm{P}<0,005$ artinya ada perbedaan yang signifikan pengetahuan responden antara kelompok kontrol dengan kelompok perlakuan. 


\section{Sikap}

Tabel. 15

Analisis Hasil Pret Tes Sikap Responden pada Kelompok Kontrol dan Perlakuan tentang Enam Sasaran Keselamatan Pasien

\begin{tabular}{lccccc}
\hline Sikap & $\mathrm{n}$ & Mean & Std. Deviasi & Std.error & P Value \\
\hline Kontrol & 15 & 52,53 & 15,282 & 3,946 & \multirow{2}{*}{0,116} \\
Perlakuan & 15 & 59,60 & 6,468 & 1,670 & \\
\hline
\end{tabular}

Berdasarkan tabel 15 menunjukan pada tahap pre-test nilai rata-rata sikap responden tentang enam sasaran keselamatan pasien lebih tinggi pada kelompok perlakuan dibandingkan dengan kelompok kontrol. Hasil uji statistik didapatkan pada variabel sikap dengan nilai $\mathrm{P}=0,116$ berarti tidak ada perbedaan yang signifikan sikap responden antara kelompok kontrol dengan kelompok perlakuan.

Tabel. 16

Analisis Hasil Post Tes Sikap Responden pada Kelompok Kontrol dan Perlakuan tentang Enam Sasaran Keselamatan Pasien

\begin{tabular}{lccccc}
\hline Sikap & $\mathrm{n}$ & Mean & Std. Deviasi & Std.error & P Value \\
\hline Kontrol & 15 & 51,27 & 4,652 & 1,201 & \multirow{2}{*}{0,0001} \\
Perlakuan & 15 & 58,80 & 3,745 & 0,967 & \\
\hline
\end{tabular}

Berdasarkan tabel 16 menunjukan pada tahap post-test nilai rata-rata sikap responden tentang enam sasaran keselamatan pasien lebih tinggi pada kelompok perlakuan dibandingkan dengan kelompok kontrol. Hasil uji statistik didapatkan pada variabel sikap dengan nilai $\mathrm{P}=0,0001$ berarti pada alpha $5 \%$ maka nilai $\mathrm{P}<0,005$ artinya ada perbedaan yang signifikan sikap responden antara kelompok kontrol dengan kelompok perlakuan.

\section{Tindakan}

Tabel. 17

Analisis Hasil Pre Tes Tindakan Responden pada Kelompok Kontrol dan Perlakuan tentang Enam Sasaran Keselamatan Pasien

\begin{tabular}{lccccc}
\hline Tindakan & $\mathrm{n}$ & Mean & Std. Deviasi & Std.error & P Value \\
\hline Kontrol & 15 & 14,73 & 11,035 & 2,849 & \multirow{2}{*}{0,057} \\
Perlakuan & 15 & 20,67 & 3,478 & 0,898 & \\
\hline
\end{tabular}

Berdasarkan tabel 17 menunjukan pada tahap pre tes nilai rata-rata tindakan responden tentang enam sasaran keselamatan pasien lebih tinggi pada kelompok perlakuan dibandingkan dengan kelompok kontrol. Hasil uji statistik didapatkan pada variabel tindakan dengan nilai $\mathrm{P}=0,057$ tidak ada perbedaan yang signifikan tindakan responden antara kelompok kontrol dengan kelompok perlakuan.

Tabel. 18

Analisis Hasil Post Tes Tindakan Responden pada Kelompok Kontrol dan Perlakuan tentang Enam Sasaran Keselamatan Pasien

\begin{tabular}{lccccc}
\hline Tindakan & $\mathrm{n}$ & Mean & Std. Deviasi & Std.error & P Value \\
\hline Kontrol & 15 & 28,93 & 4,217 & 1,089 & \multirow{2}{*}{0,0001} \\
Perlakuan & 15 & 39,60 & 3,376 & 0,872 & \\
\hline
\end{tabular}


Berdasarkan tabel 18 menunjukan pada tahap pos tes nilai rata-rata tindakan responden tentang enam sasaran keselamatan pasien lebih tinggi pada kelompok perlakuan dibandingkan dengan kelompok kontrol. Hasil uji statistik didapatkan pada variabel tindakan dengan nilai $\mathrm{P}=0,0001$ berarti pada alpha 5\% maka nilai $\mathrm{P}<0,005$ artinya ada perbedaan yang signifikan tindakan responden antara kelompok kontrol dengan kelompok perlakuan.

Tabel. 19

Analisis Perilaku Mahasiswa dengan Menggunakan Modul Enam Sasaran Keselamatan Pasien

\begin{tabular}{|c|c|c|c|c|c|c|}
\hline \multirow[t]{2}{*}{ Variabel } & \multirow[t]{2}{*}{ Mean } & \multirow{2}{*}{$\begin{array}{c}\text { Std. } \\
\text { Deviasi }\end{array}$} & \multicolumn{2}{|c|}{$95 \% \mathrm{CI}$} & \multirow[t]{2}{*}{$\mathrm{t}$} & \multirow[t]{2}{*}{$P$ value } \\
\hline & & & Lower & Upper & & \\
\hline $\begin{array}{l}\text { Pengetahuan } \\
\text { Kontrol - Perlakuan }\end{array}$ & -1.633 & 3.899 & -3.089 & -0.177 & -2.294 & 0.029 \\
\hline $\begin{array}{l}\text { Sikap } \\
\text { Kontrol-perlakuan }\end{array}$ & 1.033 & 11.415 & -3.229 & 5.296 & 0.496 & 0.624 \\
\hline $\begin{array}{l}\text { Penerapan } \\
\text { Kontrol-Perlakuan }\end{array}$ & -16.567 & 7.412 & -19.335 & -13.799 & -12.242 & 0.0001 \\
\hline
\end{tabular}

Berdasarkan tabel 19 menunjukan ada perbedaan yang signifikan pengetahuan (0.029) dan penerapan (0.0001) enam sasaran keselamatan pasien antara mahasiswa yang menggunakan modul dengan yang tidak menngunakan modul. Berdasarkan nilai rata-rata terjadi peningkatan nilai rata-rata pengetahuan pada kelompok perlakuan (2.294) dibandingkan kelompok kontrol. Demikian pula dalam penerapan terdapat perbedaan nilai rata-rata (12.242). Variabel sikap menunjukan tidak ada perbedaan antara yang menggunakan modul dengan yang tidak menggunakan modul (0.624).

\section{PEMBAHASAN}

\section{Tingkat Pengetahuan}

Hasil penelitian ditemukan pada penilaian awal tingkat pengetahuan mahasiswa keperawatan tentang enam sasaran keselamatan pasien pada kelompok kontrol dan perlakuan masih rendah. Pada kelompok kontrol sebagian besar rendah sedangkan pada kelompok perlakuan hampir seluruhnya rendah. Hasil penelitian ini menunjukan bahwa kesiapan mahasiswa untuk menerapkan enam sasaran keselamatan pasien pada tatanan klinik masih belum optimal.

Sasaran keselamatan pasien meliputi tercapainya hal-hal yang berkaitan dengan mengidentifikasi pasien dengan benar, meningkatkan komunikasi yang efektif, meningkatkan keamanan obat-obatan yang harus diwaspadai, memastikan lokasi pembedahan yang benar, prosedur yang benar, pembedahan pada pasien yang benar dan mengurangi risiko infeksi akibat perawatan kesehatan serta mengurangi risiko cedera pasien akibat terjatuh (Mawardi, 2019).

Hasil penelitian yang dilakukan oleh Aprilia tentang pengetahuan mahasiswa keperawatan tentang sasaran keselamatan pasien memperoleh hasil dimana terdapat $15,5 \%$ anak memiliki pengetahuan yang buruk, 69\% memiliki pengetahuan yang baik (Nuryanti, 2018).

Hal ini juga sejalan dengan penelitian yang dilakukan oleh Fraditha (2019) diperoleh uji koefisien korelasi sebesar 0,492 dengan nila $p$ value $0,000(p>0,05)$, sehingga terdapat hubungan positif yang mengartikan bahwa tingkat penegetahuan mahasiswa memeiliki hubungan dengan pelaksanaan keselamatan pasien dirumah sakit (Fraditha, 2019). Hasil 
penelitian menunjukan betapa pentingnga penegetahuan tentang keselamatan pasien terhadap mahasiswa.

Mahasiswa keperawatan sebelum masuk ketatanan pelayanan sudah dibekali tentang enam sasaran keselamatan pasien dalam mata kuliah Manajemen Patient Safety dalam bentuk teori 2 SKS. Metode pembelajaran dalam bentuk teori hanya lebih banyak memberikan pemahaman kognitif, sedangkan untuk dapat menerapkan teori tersebut memerlukan bentuk pembelajaran dengan pengalaman praktek di laboratorium maupun di klinik. Hasil penelitian ini menunjukan perlunya peninjauan ulang tentang metode pembelajaran untuk mata kuliah Manajemen Patient Safety. Media pembelajaran juga merupakan hal yang penting dalam pembelajaran. Terkait dengan keselamatan pasien salah satunya adalah modul.

Berdasarkan jawaban mahasiswa terhadap kuesioner yang diberikan banyak mahasiswa yang tidak mengetahui cara identifikasi resiko DNR, memberikan tanda cap readback pada pesan yang diterima, meminta tandatangan pemberi pesan sebagai hasil readback dalam waktu 24 jam. Selanjutnya memberi stiker untuk obat LASA dan obat sitostatika dan cuci tangan dengan cara hand rub dan assesment resiko jatuh serta tindakan pencegahan umum resiko jatuh.

Ketidaktahuan mahasiswa akan mempengaruhi sikap dan tindakan mahasiswa dalam penerapan enam sasaran keselamatan pasien. Penerimaan perilaku baru atau adopsi perilaku melalui proses yang didasari oleh pengetahuan, kesadaran dan sikap yang positif, maka perilaku tersebut akan bersifat langgeng (long lasting) daripada perilaku yang tidak didasari oleh pengetahuan (Basabih, 2018). Pengetahuan atau kognitif merupakan domain yang sangat penting dalam membentuk tindakan seseorang dalam hal ini pengetahuan yang tercakup dalam domain kognitif mempunyai 6 tingkatan (Abdul et al., 2020).

\section{Sikap}

Hasil penelitian dalam bentuk pre-test (sebelum mahasiswa berpraktik dan sebelum perlakuan) didapatkan mahasiswa keperawatan sebagian besar bersikap negatif terhadap enam sasaran keselamatan pasien pada kelompok kontrol dan kurang dari separuh dari kelompok perlakuan. Hasil penelitian ini menunjukan bahwa mahasiswa masih belum mengaggap enam sasaran keselamatan pasien merupakan komponen yang penting dalam penyelenggaraan keselamatan pasien sebagaimana yang terdapat dalam Peraturan Menteri Kesehatan RI tentang Keselamatan Pasien nomor 11 tahun 2017.

Hasil penelitian dalam bentuk post-test didapatkan semua mahasiswa bersikap negatif pada kelompok kontrol dan kurang dari separuh pada kelompok perlakuan. Berdasarkan jawaban mahasiswa terhadap kuesioner penelitian didapatkan mahasiswa menyatakan komunikasi SBAR sulit untuk dilaksanakan. Mahasiswa setuju tidak perlu identifikasi pasien akan operasi, karena operasi adalah tugas dokter. Selanjutnya mahasiswa juga bersikap bahwa tidak semua pasien beresiko jatuh.

Sikap mahasiswa yang negatif tentu akan berpengaruh terhadap tindakan dalam penerapan enam sasaran keselamatan pasien. Mahasiswa yang bersikap negatif terhadap hal di atas akan menyebabkan tidak akan melakukan komunikasi SBAR, kesalahan dalam membawa pasien yang akan dioperasi dan tidak melakukan pencegahan terhadap resiko jatuh pada pasien (Helsanewa et al., 2019). 


\section{Tindakan}

Hasil penelitian didapatkan mahasiswa keperawatan belum mampu menerapkan sasaran keselamatan pasien yang berkaitan dengan kegiatan pengurangan resiko infeksi terkait pelayanan kesehatan dan pengurangan pasien resiko jatuh. Berkaitan dengan komunikasi efektif dengan tenaga kesehatan yang menggunakan metode SBAR dan TBAK, keamanan obat dan kepastian tepat lokasi, tepat prosedur tepat pasien operasi di rumah sakit diukur tidak langsung berhubungan dengan pasien. Pengukuran dilakukan hanya melalui peragaan (Neri et al., 2018).

Kemampuan mahasiswa dalam melakukan tindakan memerlukan keterampilan yang selalu diulang. Observasi yang dilakukan hanya satu kali dan jarak antara pre-test dan posttes hanya sembilan hari, sehingga perubahan kemampuan dalam menerapkan sasaran keselamatan pasien tidak terlalu banyak perubahannya.

Penerapan enam sasaran keselamatan pasien sangat penting, karena dapat menghindari kejadian tidak diharapkan, kejadian cedera atau kejadian nyaris cedera. Dalam penerapan selain media berupa modul juga diperlukan media elektronik seperti vidio, sehingga mahasiswa dapat mempraktikan sebelum praktik di rumah sakit. Selain itu preseptor keperawatan harus menjadi model dalam penerapan enam sasaran keselamatan pasien (Kurniasih \& Natalia, 2018).

\section{Perbedaan Pengetahuan antara Kontrol dan Perlakuan}

Hasil penelitian ditemukan tidak ada perbedaan pengetahuan antara kelompok kontrol dengan kelompok perlakuan pada pengukuran awal (pre-test). Hal ini menunjukan bahwa sampel penelitian kelompok kontrol dan perlakuan dalam keadaan pengetahuan awal yang relatif sama.

Hasil penelitian setelah diberikan perlakuan berupa modul pada kelompok perlakuan didapatkan ada perbedaan yang bermakna, kelompok perlakuan rata-rata pengetahuannya lebih tinggi dibandingkan dengan kelompok kontrol. Hal ini menunjukan bahwa penggunaan modul enam sasaran keselamatan pasien dapat meningkatkan pengetahuan mahasiswa tentang sasaran keselamatan pasien.

\section{Perbedaan Sikap antara Kontrol dan Perlakuan}

Hasil penelitian ditemukan tidak ada perbedaan sikap antara kelompok kontrol dengan kelompok perlakuan pada pengukuran awal (pre-test). Hal ini menunjukan bahwa sampel penelitian kelompok kontrol dan perlakuan dalam keadaan awal sikap yang relatif sama.

Hasil penelitian setelah perlakuan pada kelompok perlakuan didapatkan ada perbedaan yang bermakna. Kelompok perlakuan rata-rata memiliki sikap yang lebih tinggi dibandingkan dengan kelompok kontrol. Hal ini menunjukan bahwa penggunaan modul enam sasaran keselamatan pasien dapat meningkatkan sikap yang positif bagi mahasiswa tentang sasaran keselamatan pasien.

\section{Perbedaan Tindakan antara Kontrol dan Perlakuan}

Hasil penelitian ditemukan tidak ada perbedaan kemampuan antara kelompok kontrol dengan kelompok perlakuan pada pengukuran awal (pre-test). Hal ini menunjukan bahwa sampel penelitian kelompok kontrol dan perlakuan dalam kemampuan awal yang relatif sama.

Hasil penelitian setelah diberikan perlakuan pada kelompok perlakuan didapatkan ada perbedaan yang bermakna antara kelompok perlakuan dengan kelompok kontrol. Kelompok perlakuan rata-rata kemampuannya lebih tinggi dibandingkan dengan kelompok 
kontrol. Hal ini juga sejalan dengan penelitian yang dilakukan Supatri (2018) tentang pengaruh penyampaian pasien safety terhadap pengetahuan mahasiswa Keperawatan Universitas Muhammadiyah Purwokerto, yang menunjukan bahwa terdapat peningkatan rerata tingkat penegetahuan mahasiswa sebelum dan sesudah diberikan materi tersebut. Hal ini menunjukan bahwa penggunaan modul enam sasaran keselamatan pasien dapat meningkatkan kemampuan mahasiswa dalam menerapkan sasaran keselamatan pasien.

\section{Analisis Efektifitas Penggunaan Modul Enam Sasaran Keselamatan Pasien}

Hasil penelitian menunjukan bahwa kelompok atau mahasiswa yang mengunakan Modul enam sasaran keselamatan pasien dalam pembelajaran di klinik terjadi peningkatan pengetahuan, dan begitu pula dengan penerapan enam sasaran keselamatan pasien. Namun pada sikap tidak menunjukan perbedaan antara mahasiswa yang menggunakan modul dengan mahasiswa yang menggunakan modul.

Hasil penelitian ini menunjukan bahwa modul enam sasaran keselamatan pasien dapat digunakan untuk meningkatkan pengetahuan dan tindakan. Namun belum efektif dalam merubah sikap. Perubahan sikap memerlukan waktu yang lebih panjang atau lebih lama, sehingga perubahan dalam waktu dua minggu belum dapat dinilai.

Efektifitas modul juga dipengaruhi oleh isi dan cara penyajian. Ada beberapa pengetahuan dan tindakan yang tidak mengalami peningkatan sehingga isi dan penyajian modul masih perlu untuk disempurnakan atau dimodifikasi.

\section{SIMPULAN}

Terdapat perbedaan pengetahuan, sikap dan tindakan yang signifikan antara mahasiswa yang diberikan perlakuan berupa modul enam sasaran keselamatan pasien dengan yang tidak diberikan. Modul enam sasaran keselamatan pasien dapat meningkatkan perilaku mahasiswa keperawatan dalam penerapan sasaran keselamatan pasien di rumah sakit. Modul enam sasaran keselamatan pasien efektif dalam peningkatan pengetahuan dan tindakan dalam penerapan sasaran keselamatan pasien.

\section{SARAN}

Disarankan kepada mahasiswa, dosen dan preceptor keperawatan untuk menggunakan modul enam sasaran keselamatan pasien yang telah disempurnakan atau dimodifikasi dalam proses pembelajaran klinik untuk menerapkan enam sasaran keselamatan pasien yang merupakan salah satu unsur penting dalam penyelenggarakan keselamatan pasien.

Disarankan kepada peneliti selanjutnya untuk melakukan penelitian dengan metoda yang berbeda tentang efektifitas penggunaan modul enam sasaran keselamatan pasien dengan membandingkan antara modul dan aplikasi/ video.

\section{DAFTAR PUSTAKA}

Abdul, A., Saleh, A., \& Sjattar, E. L. (2020). Hubungan Perilaku Caring Perawat dengan Tingkat Kepuasan Pasien Rawat Inap di Rumah Sakit Harapan Bunda Kota Batam. Jurnal Keperawatan Muhammadiyah, I(5), 283-288. http://103.114.35.30/index.php/JKM/article/view/4918

Basabih, M. (2018). Perlukah Keselamatan Pasien Menjadi Indikator Kinerja RS BLU. Jurnal ARSI, 3(2), 150-157. https://journal.fkm.ui.ac.id/arsi/article/view/2220 
Budi, S. C., Sunartini, S., Lazuardi, L., \& Tetra, F. S. (2019). Tren Insiden Berdasarkan Sasaran Keselamatan Pasien. Jurnal Manajemen Informasi Kesehatan Indonesia, 7(2), 146. https://doi.org/10.33560/jmiki.v7i2.236

Faluzi, A., Machmud, R., \& Arif, Y. (2019). Analisis Penerapan Upaya Pencapaian Standar Sasaran Keselamatan Pasien bagi Profesional Pemberi Asuhan dalam Peningkatan Mutu Pelayanan di Rawat Inap RSUP Dr. M. Djamil Padang. Jurnal Kesehatan Andalas, 7(4), 34-43. DOI: 10.25077/jka.v7i0.919

Fenita, R. (2019). Penerapan 6 Sasaran Keselamatan Pasien di RSUD Rasidin dan RS . Bhayangkara. E-Skripsi Andalas. http://scholar.unand.ac.id/45527/

Fraditha, S. (2019). Hubungan antara Pengetahuan Mahasiswa Praktikan tentang Keselamatan Pasien dengan Pelaksanaan Penilaian Resiko Jatuh di Rumah Sakit Sultan Agung Semarang. Universitas Islam Sultan Agung Semarang. http://repository.unissula.ac.id/14674/

Haritsa, A. I., \& Haskas, Y. (2021). Evaluasi Pelaksanaan Keselamatan Pasien (Pasien Safety) di Rumah Sakit Umum Daerah Labuang Baji Makassar. JIMPK: Jurnal Ilmiah Mahasiswa \& Penelitian Keperawatan, 1(1), 59-66. http://jurnal.stikesnh.ac.id/index.php/jimpk/article/view/495

Helsanewa, A., Rifai, A., \& Jamaluddin, J. (2019). Studi Deskriftif Pelaksanaan Sasaran Keselamatan Pasien Sesuai Instruksi Kars Versi 2012 di IGD Rumah Sakit TNI AD Tk IV 02.07.04 Bandar Lampung. Jurnal Ilmu Kesehatan Masyarakat, 8(03), 100108. https://doi.org/10.33221/jikm.v8i03.300

Jelita, W. (2019). Hubungan Kepemimpinan Transformasional Kepala Ruangan dengan Penerapan Keselamatan Pasien di Ruang Rawat Inap Interne, Paru dan Anak RSUD DR. M. Zein Painan. Universitas Perintis. http://repo.upertis.ac.id/825/

Kurniasih, K., \& Natalia, T. P. (2018). Efektivitas Penerapan Art Therapy dalam Meningkatkan Self-Esteem pada Remaja di Lembaga X. Jurnal Muara Ilmu Sosial, Humaniora, dan Seni, 2(1), 215. https://doi.org/10.24912/jmishumsen.v2i1.1585

Mawardi, A. (2019). Analisis Pelaksanaan Ketepatan Identifikasi Pasien Berdsarkan Standar Sasaran Keselamatan Pasien Di Rumah Sakit Surya Insani Pasir Pengaraian Tahun 2019. Institut Kesehatan Helvetia, 1(1), 2-8. http://repository.helvetia.ac.id/id/eprint/2565

Mudayana, A. A., \& Juniarti, N. H. (2018). Penerapan Standar Keselamatan Pasien di Rumah Sakit Umum Daerah Provinsi Nusa Tenggara Barat. Jurnal Kesehatan Poltekkes Ternate, 11(2), 93-108. http://ejournal.poltekkesternate.ac.id/ojs/index.php/juke/article/view/91

Neri, R. A., Lestari, Y., \& Yetti, H. (2018). Analisis Pelaksanaan Sasaran Keselamatan Pasien di Rawat Inap Rumah Sakit Umum Daerah Padang Pariaman. Jurnal Kesehatan Andalas, 7(4), 48-55. DOI: 10.25077/jka.v7i0.921

Nugraheni, S. W., Yuliani, N., \& Velina, A. D. (2021). Studi Literatur: Budaya Keselamatan Pasien dan Insiden Keselamatan Pasien di Rumah Sakit. Prosiding Seminar Informasi Kesehatan Nasional, 1(2018), 290-295. https://ojs.udb.ac.id/index.php/sikenas/article/view/1264

Nuryanti, A. (2018). Undergraduate Nursing Students Knowledge about Patient Safety. Jurnal Ilmiah Keperawatan (Scientific Journal of Nursing), 5(2), 86-91. DOI: 10.33023/jikep.v5i2.237 
Sapardi, S., Machmud, R., \& Gusti, R. P. (2018). Analisis Pelaksanaan Manajemen Pencegahan dana Pengendalian Healthcare Associated Infections di RSI Ibnusina. Jurnal Endurance, 3(2), 358-366. http://ejournal.lldikti10.id/index.php/endurance/article/view/3029

Supatri, S. (2018). Pengaruh Penyampaian Pasien Safety terhadap Pengetahuan Mahasiswa Keperrawatan Universitas Muahammadiyah Purwokerto. SAINTAEKS, 15(2), 131136. http://jurnalnasional.ump.ac.id/index.php/SAINTEKS/article/view/6310

Surahmat, R., Neherta, M., \& Nurariati, N. (2019). Hubungan Supervisi Dengan Implementasi Sasaran Keselamatan Pasien Di Rumah Sakit Muhammadiyah Palembang. Proceeding Seminar Nasional Keperawatan, 4(1), 173-178. http://conference.unsri.ac.id/index.php/SNK/article/view/1210 